\title{
CONHECIMENTOS, PRÁTICAS E ATITUDES FRENTE AO DIAGNÓSTICO DE CÂNCER DE BOCA NA VISÃO DO CIRURGIÃO-DENTISTA
}

Ana Paula Sapata MOLINA; Mariana Gomes RIBEIRO; Josiane Aparecida da SILVA; Cassius Carvalho TORRES-PEREIRA

Este estudo avaliou o conhecimento, práticas e atitudes de cirurgiões-dentistas (CDs) em Curitiba em relação às doenças bucais a fim de identificar o índice de CDs que exercem a Estomatologia na sua rotina clínica e verificar seu grau de conscientização sobre a importância do diagnóstico precoce de lesões malignas. Questionários foram aplicados por 3 examinadores no ambiente de trabalho de 100 CDs, selecionados através de randomização dos números de registro no Conselho Regional de Odontologia do Paraná. A doença bucal mais freqüentemente diagnosticada foi a afta (85\%). Estão preparados para diagnosticar doenças bucais $54 \%$ dos entrevistados. Do total, $44 \%$ são procurados por pacientes que buscam tratamento para lesões bucais. Tratam doenças da boca $66 \%$ dos CDs, $19 \%$ os encaminham para serviços especializados e $15 \%$ não souberam responder. Os fatores mais importantes para suspeitar de câncer bucal foram: tempo de evolução (40\%) e linfonodos palpáveis (38\%). O interesse em se atualizar em patologia bucal foi confirmado por $86 \%$ dos dentistas, 4\% não se atualizariam por "falta de interesse", 4\% por "área de atuação diversa da Estomatologia" e 2\% por "encerramento de carreira". Os resultados refletiram descuido de alguns CDs com a completa avaliação do estado de saúde bucal dos seus pacientes. 